\title{
A utilização da metodologia FMEA e SLP para priorização de riscos ocupacionais: um estudo de caso realizado em um laboratório de pesquisa
}

Estela Vitória da Silva e Silva estelavitoriaeng@gmail.com

Universidade do Estado do Pará (UEPA), Marabá, Pará, Brasil

Samantha Costa de Sousa samanthacsousa@hotmail.com Universidade do Estado do Pará (UEPA), Marabá, Pará, Brasil

\section{Sarah Nascimento Ribeiro} sarahnasc.ri@hotmail.com Universidade do Estado do Pará (UEPA), Marabá, Pará, Brasil

Tiago Silva dos Santos tiagosilvaep2015@gmail.com Universidade do Estado do Pará (UEPA) Marabá, Pará, Brasil

\section{Nathália Jucá Monteiro} nathalia2210@yahoo.com.br Universidade do Estado do Pará (UEPA), Belém, Pará, Brasil

\begin{abstract}
RESUMO
A legislação brasileira define parâmetros e propõe métodos que visam a garantia da saúde e segurança no trabalho. Dentre estes métodos, está o mapeamento de riscos de acidentes. Neste artigo foi abordada a aplicação do modelo FMEA (Failure Mode and Effects Analysis) que juntamente com o mapa de risco vislumbraram informações essenciais sobre as probabilidades de ocorrência de acidentes e as possíveis gravidades dos riscos em um laboratório de polímeros e processos de transformações de materiais, de um centro universitário no sudeste do estado do Pará, no município de Marabá. Houve uma visão detalhada dos processos do ambiente estudado, e com isso, propostas de melhorias ao layout foram dadas através da aplicação da metodologia SLP (Systematic Layout Planning). Logo, esta pesquisa teve como objetivo analisar as condições em relação a segurança do trabalho, as disponibilidades de equipamentos de proteção, e além disso se propôs um modelo de mapa de risco, layout planejado e um parâmetro de possíveis falhas que podem proporcionar maiores ricos ocupacionais, tornando assim os profissionais e acadêmicos, que atuam no laboratório, menos vulneráveis a acidentes. Após a aplicação do SLP foram elaboradas duas propostas de layout, sendo que a segunda foi a escolhida em função de atender melhor aos critérios estabelecidos, além de ter melhorado o espaço para circulação e a segurança do local.
\end{abstract}

PALAVRAS-CHAVE: SLP. FMEA. Mapa de risco. Laboratório. 


\section{INTRODUÇÃO}

A busca pela garantia da segurança e saúde dos colaboradores vem sendo prioridade para qualquer tipo de organização. De acordo com Cavalcanti et al. (2017), os acidentes de trabalho constituem o principal agravo à saúde dos trabalhadores, com elevados custos sociais e econômicos, que podem chegar a $10 \%$ do Produto Interno Bruto (PIB). Ainda segundo o autor, esses acidentes são influenciados por aspectos da situação imediata de trabalho como o maquinário, a tarefa, o meio técnico ou material, e também pelas relações de trabalho, cuja determinação situa-se na organização.

O planejamento do layout, ou arranjo físico, apresenta-se como um aspecto que pode conferir melhorias decisivas, pois define o fluxo otimizado nos processos de um ambiente. Assim, o planejamento e a mudança de layout desempenham um papel importante na prevenção das probabilidades de ocorrência de acidentes e das possíveis gravidades dos riscos juntamente com uma devida elaboração de um mapa de risco, contribuindo fortemente para a organização de qualquer local (SANTOS et al., 2018).

Para diminuir os riscos que os trabalhadores estão expostos é fundamental a aplicação de ferramentas de gerenciamento de risco laboral (SALIBA, 2018). Com a intenção de identificar os riscos antes da execução do trabalho, existem ferramentas bastante difundidas como análise ergonômica de tarefa, análise da árvore de falhas, análise preliminar de risco e o FMEA (failure mode and effects analysis) (CASOTTI et al., 2017). O FMEA, ou modo de falha e análise de efeitos, é um dos métodos de avaliação de falhas, que correlacionam suas causas e efeitos, pontuando também os meios de sua detecção, prevenção e mitigação de efeitos (BARBOZA et al., 2017). A maioria das ferramentas de análise é capaz de pontuar qualitativamente quais os riscos presentes na execução daquela tarefa estudada, além de considerar as causas iniciais do risco e indicar medidas corretivas. Contudo, não indicam de modo quantitativo o quão grande aquele risco identificado pode se tornar, nem elencam numericamente quais modalidades de falha se destacam como principal. Neste sentido foi utilizado o FMEA, uma ferramenta de análise de risco para sistemas e processos que, através de análise quantitativa, consegue ranquear prioridades.

É importante que haja também a análise do layout e do mapa de risco do laboratório de polímeros e processos de transformações de materiais, que é um ambiente onde servidor e acadêmico estão sujeitos a agentes químicos, físicos, biológicos, ergonômicos e de acidente, os quais constituem riscos ocupacionais. Desta forma, esta pesquisa justifica-se por estar contribuindo com o bem-estar humano, e na constância de uma sociedade cientifica que promove a divulgação do conhecimento, colaborando para um sistema de gestão em segurança e saúde do trabalho no centro universitário. Diante desse cenário, o presente trabalho busca responder a seguinte pergunta de pesquisa: Como o SLP pode auxiliar na elaboração de layouts para um laboratório de pesquisa?

O presente estudo é resultado de uma pesquisa quantitativa, qualitativa, exploratória e descritiva, que tem por objetivo realizar a análise de risco do laboratório de polímeros, por meio das ferramentas de classificação de risco, elaborando o Mapa de Risco que permite fazer um diagnóstico da situação de segurança e saúde do trabalho com a finalidade de estabelecer medidas preventivas, além da aplicação do FMEA. Neste sentido este trabalho contribuiu 
para a análise de riscos através da aplicação do FMEA na segurança do trabalho, e ainda elabora propostas de modelos de layouts, por meio da análise SLP. O estudo está estruturado da seguinte forma: na seção 2 apresenta-se a fundamentação teórica, na seção 3 como o estudo foi aplicado, na seção 4 análise e síntese dos resultados e por fim, na seção 5 as considerações finais deste trabalho.

\section{REFERENCIAL TEÓRICO}

Neste tópico serão apresentados os assuntos pertinentes para a execução do trabalho. Vale ressaltar que o objetivo do mesmo não é discutir extensivamente o assunto, mas apresentar uma breve discussão sobre os temas abordados na pesquisa.

\section{HIGIENE E SEGURANÇA DO TRABALHO}

A higiene e segurança do trabalho é o conjunto de normas e procedimentos voltado para a integridade física e mental do trabalhador, preservando-o dos riscos de saúde inerentes às tarefas do cargo e ao ambiente físico onde são executadas (CHIAVENATO, 1999). O termo higiene é utilizado no sentido de evitar doenças, e como expressões de "Segurança e Higiene Ocupacional" e "Segurança e Higiene do Trabalho".

A segurança do trabalho integra um conjunto de metodologia que agem diretamente no campo de reconhecimento e controle dos riscos associados ao local de trabalho e processos produtivos. Por outro lado, a higiene atua no reconhecimento e controle dos riscos biológicos também influenciados pelo posto de trabalho e suas tarefas (PONZETTO, 2007).

Segundo o conselho regional do Rio de Janeiro de engenharia e segurança do trabalho (2013), a higiene e segurança do trabalho podem ser entendidas como "conjuntos de medidas que são adotadas com o objetivo de minimizar os riscos no ambiente do trabalho, relacionados a doenças ocupacionais, bem como proteger a integridade e a capacidade laboral do trabalhador".

Reconhecer os riscos ocupacionais é o primeiro passo para elaborar e implementar um projeto de segurança do trabalho. Com o intuito de manter a qualidade de vida dos trabalhadores, especialmente os que atuam em locais insalubres, um programa estruturado de higiene e segurança do trabalho é essencial, para que isso ocorra, conforme Antão (2014), os seguintes passos devem ser seguidos:

- A manutenção da saúde;

- Eliminação das causas das doenças profissionais;

- Prevenção do agravamento de doenças e lesões;

- Manutenção de ambientes de trabalho saudáveis e produtivos;

- Aumento da produtividade pelo controle do ambiente de trabalho;

- Valorização do elemento humano como parte primordial para o sucesso de qualquer organização. 


\section{NORMAS REGULAMENTADORAS - NRS}

O Ministério do Trabalho e Emprego publicou em 8 de junho de 1978 a portaria no 3.124 as Normas Regulamentadoras de Segurança e Saúde no Trabalho, as NRs. Em 1978 eram 28 Normas Regulamentadoras, atualmente, são 35 em vigor.

De acordo com De Castro (2016), a possibilidade da saúde ou integridade física de um funcionário sofrer algum prejuízo durante a execução de suas atividades profissionais é chamada de risco ocupacional. A maioria desses riscos está associada aos ambientes em que o trabalhador fica exposto a ruídos, vibrações, gases, iluminação inadequada ou outras situações que podem colocar a saúde em risco.

Os riscos no ambiente laboral podem ser classificados em cinco tipos, de acordo com a Portaria no 3.214, do Ministério do Trabalho do Brasil, de 1978. Esta Portaria contém uma série de normas regulamentadoras que consolidam a legislação trabalhista, relativas à segurança e medicina do trabalho. A classificação dos riscos encontra-se na Norma Regulamentadora 05 e 09 (NR-5) expresso no Quadro 1.

Quadro 1 - Riscos ambientais, conforme a NR-5

\begin{tabular}{|c|c|}
\hline Físicos & $\begin{array}{c}\text { Consideram-se agentes de risco físico as diversas formas de energia a } \\
\text { que possam estar expostos os trabalhadores, tais como: ruído, calor, } \\
\text { frio, pressão, umidade, radiações ionizantes e não ionizantes, } \\
\text { vibração etc. }\end{array}$ \\
\hline Químicos & $\begin{array}{l}\text { Consideram-se agentes de risco químico as substâncias, compostos } \\
\text { ou produtos que possam penetrar no organismo do trabalhador pela } \\
\text { via respiratória, nas formas de poeiras, fumos gases, neblinas, } \\
\text { névoas ou vapores, ou que seja, pela natureza da atividade, de } \\
\text { exposição, possam ter contato ou ser absorvido pelo organismo } \\
\text { através da pele ou por ingestão. }\end{array}$ \\
\hline Ergonômicos & $\begin{array}{c}\text { Qualquer fator que possa interferir nas características } \\
\text { psicofisiológicas do trabalhador, causando desconforto ou afetando } \\
\text { sua saúde. São exemplos de risco ergonômico: o levantamento de } \\
\text { peso, ritmo excessivo de trabalho, monotonia, repetitividade, } \\
\text { postura inadequada de trabalho etc. }\end{array}$ \\
\hline Biológicos & $\begin{array}{l}\text { Consideram-se como agentes de risco biológico as bactérias, vírus, } \\
\text { fungos, parasitas, entre outros. }\end{array}$ \\
\hline De acidente & $\begin{array}{l}\text { Qualquer fator que coloque o trabalhador em situação vulnerável e } \\
\text { possa afetar sua integridade, e seu bem-estar físico e psíquico. São } \\
\text { exemplos de risco de acidente: as máquinas e equipamentos sem } \\
\text { proteção, probabilidade de incêndio e explosão, arranjo físico } \\
\text { inadequado, armazenamento inadequado etc. }\end{array}$ \\
\hline
\end{tabular}

Fonte: Adaptado de PONZETTO (2007)

A norma regulamentadora $n^{\circ} 17$ (NR 17) é a norma que discorre sobre o tema Ergonomia. Nesta norma está previsto o estabelecimento de parâmetros que permitam a adaptação das condições de trabalho às características psicofisiológicas dos trabalhadores, de modo a proporcionar um máximo de conforto, segurança e desempenho eficiente. A NR 17 possui anexos que mencionam sobre o posto de trabalho adequado, as ferramentas utilizadas pelo colaborador em seu ambiente de realização de tarefas, entre outros. 


\section{PLANEJAMENTO SIMPLIFICADO DE LAYOUT (SLP)}

Há muitos métodos de planejar e alocar os recursos de transformação, e um dos mais usados é o sistema SLP, planejamento simplificado do layout. Nesse método, a maior preocupação é definir a posição das máquinas, equipamentos e pessoas, de forma eficiente. De acordo com Pereira et al. (2014), o sistema SLP utiliza uma sequência de procedimentos específicos para desenvolver inicialmente, de forma sistemática, um layout de blocos, a fim de obter informações de cada setor planejado.

De acordo com Muther (2000), o Planejamento Simplificado do Layout (SLP) é um conjunto de métodos e fases que visam identificar, analisar e avaliar a posição de todos os elementos e áreas envolvidas em uma linha de produção. Para isto ocorrer de forma efetiva, segundo Santos et al. (2018), antes de realizar qualquer planejamento de layout, é de suma importância que todas as informações relacionadas com o processo produtivo e com o fluxo de materiais devem ser levantadas e repassadas.

Segundo Favoni et al. (2013), esta ferramenta irá auxiliar os indivíduos na tomada de decisão em relação ao melhor posicionamento das instalações, máquinas, equipamentos e pessoas na linha de produção e processo produtivo. Para que isso ocorra, o SLP inicia com uma análise baseada nas iniciais PQRST (produto, quantidade, rota, suporte e tempo). Essa análise auxilia na coleta organizada dos dados do problema em questão.

Segundo Muther et al. (2000), o método SLP tem como objetivo identificar dentre vários cenários, aquele layout que mais se adequa a realidade da empresa, ou seja, o que mais se ajusta as necessidades. Este método, é divido em três fases, a primeira fase é a de análise que inicia com a avaliação do fluxo de materiais por meio de uma planilha, onde estas possuem informações acerca do fluxo de materiais entre os departamentos. Posteriormente, inicia-se a fase da análise das atividades, essas são relacionadas e analisadas, em pares, de forma qualitativa com objetivo de decidir o grau de aproximação entre os departamentos.

A partir desta análise, o diagrama de relacionamentos, aloca e demonstra o grau de aproximação entre os departamentos, desta forma, definindo quais setores devem estar mais próximos. Diante dos resultados da análise do espaço disponível e do espaço necessário, chega-se a conclusão de quanto espaço o layout mais adequado necessita, ou seja, determina-se a quantidade de espaço que cada departamento precisa para suprir as suas necessidades de forma eficiente. Vale ressaltar, que não são levadas em consideração futuras expansões no espaço analisado. (PEREIRA et al., 2014).

Ao finalizar o estágio de análise, a fase de pesquisa inicia-se com a construção de um diagrama de relacionamento de espaço, que inclui as áreas dos departamentos ao diagrama de relacionamento. E por fim a fase de seleção inicia-se com a escolha do um arranjo físico ideal de espaços, em seguida um arranjo realístico ou otimizado é definido, no qual é possível analisar pouca variação do arranjo físico ideal e determinar qual a alternativa de layout é a mais adequada. (MUTHER et al., 2000).

O SLP é uma ferramenta de altíssima importância que além de definir qual o layout mais adequado para o espaço estudado, é considerada uma ferramenta de 
auxílio na tomada de decisão do melhor posicionamento das máquinas, equipamentos e pessoal. A metodologia SLP, de acordo com Rocha et al. (2011) é composta por quatro etapas básicas, sendo a primeira fase a determinação do local da área que será planejada, na segunda estabelece-se a posição relativa entre as diversas áreas. Já na terceira determina-se a localização de cada máquina/equipamento e as características físicas de cada área e na quarta cada passo de implantação do novo layout deve ser planejado. Muther et al. (2000) apresentam as etapas mais detalhadamente conforme abaixo:

- Dados de Entrada: São dados ou variáveis que devem ser analisadas antes de iniciar a fase de análise do arranjo físico, além das atividades do processo produtivo, estes dados são representados pelas letras PQRST, que significam: produto $(P)$, quantidade ou volume de produção $(Q)$, roteiro ou sequência do processo de produção $(\mathrm{R})$, serviços de suporte $(\mathrm{S})$ e tempos envolvidos na produção $(T)$;

- Fluxo de Materiais: Segundo Muther et al. (2000), o fluxo de materiais é um dos principais fatores que influenciam na definição do projeto do arranjo físico, portanto deve-se determinar o fluxo dos materiais por meio das áreas envolvidas, de acordo com a quantidade de vezes que este material é deslocado da área. Nesta fase, segundo Rocha et al. (2011), as principais ferramentas utilizadas são aquelas que tem como objetivo analisar o fluxo do processo, tais como: fluxograma, mapofluxograma e carta de processos múltiplos;

- Inter-relação de Atividade: Esta etapa é uma análise de cunho qualitativa, que busca relacionar, aos pares, cada atividade ou setor de acordo com um grau de proximidade relativa entre os diferentes departamentos. Desta forma, buscase a importância de cada atividade com a área, a fim de determinar a necessidade de proximidade entre os espaços. A ferramenta indicada para essa tarefa é chamada de carta de interligações preferenciais (SANTOS et al., 2018);

- Diagrama de Inter-relações: O diagrama de inter-relações é uma ferramenta que busca integrar o mapeamento do fluxo de materiais com a avaliação das diversas atividades ou departamentos, com objetivo de definir a necessidade de relacionamentos e níveis de proximidade entre os espaços, sendo os setores representados por símbolos e ligados por linhas que representam a importância da relação;

- Diagrama de Inter-relações Entre Espaços: Nesta etapa o diagrama de interrelações é aplicado a fim de gerar um layout prévio, no qual se determina e reserva a quantidade de espaço fabril a cada departamento, considerando que o espaço requerido já foi analisado a partir do disponível;

- Considerações de Mudanças e Limitações Práticas: Nesta etapa ocorrem os ajustes e modificações considerando as necessidades exigidas, levando-se em consideração os fatores relativos a tipos de processo, métodos de movimentações de materiais, necessidades de pessoal e outros. E para analisar a viabilidade do projeto do layout, cada mudança que houver, devem-se levar em consideração as limitações práticas de produção, referente a custos, restrições técnicas e segurança;

- Seleção das Propostas: Esta é a última etapa, em que as propostas de layouts, que foram elaborados durante o procedimento, serão avaliadas 
ponderando seus benefícios e limitações para que a mais ideal a ser implantada seja escolhida.

\section{FMEA - ANÁLISE DE MODO E EFEITO DE FALHA}

FMEA (Failure Mode and Effects Analysis) é uma ferramenta da gestão da qualidade desenvolvida na década de 1960 pela agência norte-americana NASA (National Aeronautics and Space Administration) durante a missão Apollo, e esse método tem por objetivo identificar falhas potenciais em sistemas, projetos, processos ou serviços, bem como seus efeitos e causas e a partir disso, definir ações para reduzir ou eliminar o risco associado a essas falhas (PEREIRA, 2012).

Essa metodologia está focada na prevenção de defeitos, aumentando a segurança e satisfação dos clientes. O ideal é que seja realizada no estágio de elaboração do desenvolvimento do produto, contudo, a mesma pode ser utilizada em produtos/serviços já existentes: A utilização do FMEA se dá nas diversas etapas de projeto de um produto (CASOTTI et al., 2017).

Dominar a técnica de Análise do Tipo e Efeito de Falha é essencial para profissionais no ramo da engenharia, pois saber reconhecer e resolver falhas e princípios de falhas faz conexão com o crescimento da empresa e manutenção do nome frente a clientes e concorrentes (ZORZAN et al., 2013).

Pereira et al. (2012) definem que existem dois tipos de FMEA: de projeto (Design FMEA-DFMEA) e de processo (Process FMEA - PFMEA). O que os tornam diferentes são as funções entradas dos processos. O DFMEA visa identificar as falhas supondo que a fabricação atenda aos requisitos do projeto (peça conforme). Já o PFMEA identifica potenciais modos de falha supondo que o projeto atenda a aplicação final (projeto correto), sendo que sua principal entrada é o DFMEA. Definem-se quatro situações as quais se pode aplicar a ferramenta, segundo Casotti et al. (2017), sendo:

- Para diminuir a probabilidade de ocorrência de falhas em projetos de novos produtos ou processos;

- Para diminuir a probabilidade de falhas potenciais (ou seja, que ainda não tenham ocorrido) em produtos/processos já em operação;

- Para aumentar a confiabilidade de produtos ou processos já em operação por meio da análise das falhas que já ocorreram;

- Para diminuir os riscos de erros e aumentar a qualidade em procedimentos administrativos.

De acordo com Barboza et al. (2017), na utilização dessa técnica várias vantagens são obtidas, entre elas: as informações que constam na ferramenta são visíveis, consequentemente se tornam de fácil entendimento para todos envolvidos; é um procedimento sistemático, podendo ser gerenciada com auxílio de software, devido à base de dados que é gerada; identifica as fraquezas do processo, visando dar foco a determinados problemas identificados; as ações ficam claramente estabelecidas e focadas em poucos componentes ou processos. 


\section{Aplicação FMEA}

O processo de aplicação da metodologia FMEA consiste em cinco etapas conforme Santos e Kawakame (2014) as definem:

- Planejamento: Compreende a etapa de definição do objetivo da avaliação, como o levantamento será realizado e a preparação da documentação;

- Análise de falhas em potencial: 0 grupo deve preencher o formulário avaliando as falhas potenciais, os efeitos, os tipos de falhas e o controle vigente;

- Avaliação de riscos: determinação dos seguintes índices para cada causa da falha: Severidade (S), Ocorrência (P), Detecção (D).

- Melhorias: A partir do conhecimento dos riscos, através do conhecimento empírico, criatividade ou outras ferramentas, como brainstorming, lista-se todas ações que podem ser realizadas para diminuir os riscos;

- Continuidade: O processo do FMEA deve ser uma atividade rotineira, após a realização de uma análise, esta deve ser revisada sempre que ocorrem alterações neste produto/serviço.

A ferramenta é formulada a partir do preenchimento de um formulário, sendo composto por nove subdivisões:

- Processo: etapa do processo a ser estudada;

- Risco Potencial: problemas que possam vir a ocorrer;

- Efeitos potenciais de falha;

- Severidade: parâmetro estipulado de 1 a 10, sendo 1 a severidade mínima e 10 a máxima;

- Causa da falha;

- Ocorrência (P): probabilidade para ocorrer a determinada falha, parâmetros de 1 a 10, sendo 1 o mínimo e 10 o máximo;

- Controle: métodos hoje utilizados pela organização para gerir esta falha;

- Detecção: capacidade de detectar a falha, parâmetro estipulado de 1 a 10, sendo 1 a capacidade de detecção muito alta e 10 muito pequena (indetectável);

- RPN- Número de Prioridade de risco: multiplicação dos valores de severidade do efeito $(S)$, à probabilidade da ocorrência $(P)$ e níveis de detecção (D).

\section{METODOLOGIA}

Para a elaboração do presente artigo, realizou-se um estudo de caso com características de uma análise quantitativa, qualitativa e exploratória. Segundo Moreira (2008), a pesquisa quantitativa considera tudo que pode ser quantificável, ou seja, as informações podem ser traduzidas em números para depois classificá-las e analisá-las. Já a qualitativa, considera que o ambiente natural é a fonte para coleta de dados, analisando-os com raciocínio indutivo. Dessa forma, foi realizada coleta de dados sobre informações relacionadas ao 
ambiente, layout do espaço, organização dos objetos e materiais no local e possíveis riscos no ambiente estudado.

De acordo com Moreira (2008), a pesquisa exploratória caracteriza-se por fazer a coleta de dados a partir de pesquisa bibliográfica, entrevista com pessoas que tiveram experiências no assunto e análise de exemplos que estimulem a compreensão. A mesma também pode ser caracterizada como pesquisa descritiva, pois visa descrever características de determinada população ou fenômeno, envolvendo técnicas de coleta de dados como questionário e observação sistemática, assumindo, em geral, a forma de levantamento. Sendo assim, durante a realização do estudo foram utilizados informações e dados de revistas, livros, artigos científicos, além de uma entrevista não estruturada com o coordenador do laboratório e dois alunos.

Foi solicitado aos entrevistados para que citassem os fatores que tornam os acidentes mais prováveis durante as aulas e atividades no laboratório em questão, e os fatores citados foram a falta de conhecimento, falta de precaução por parte do usuário do laboratório, a negligência do usuário ao deixar vidrarias e reagentes no local inadequado, distração e fadiga após várias horas de trabalho e a não utilização de equipamentos de proteção.

O objetivo deste trabalho é mensurado através da aplicação da metodologia FMEA, SLP e a análise dos riscos ocupacionais em um laboratório de polímeros e processos de transformações de materiais, de um centro universitário no município de Marabá. A Figura 1 representa as etapas para realização deste estudo.

Figura 1 - Metodologia utilizada no estudo de caso

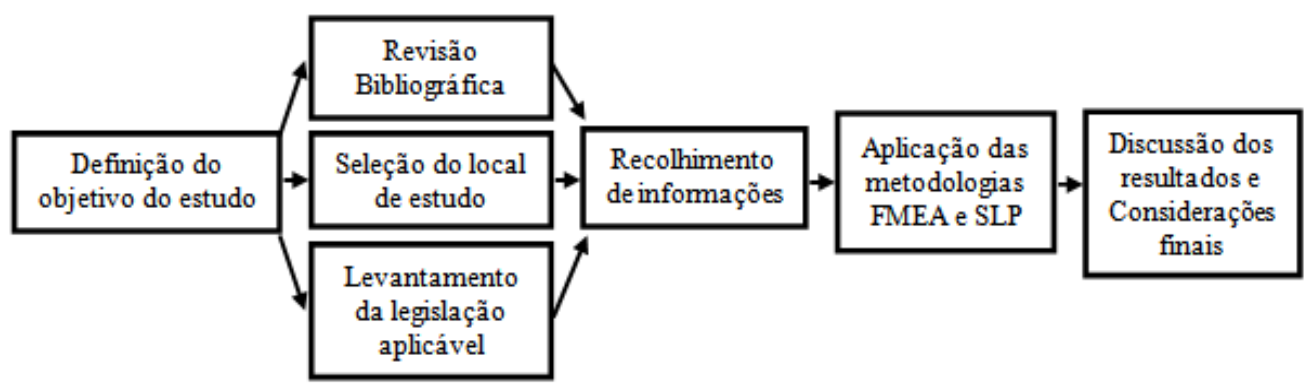

Fonte: Autoria própria (2019)

A metodologia ilustrada na Figura 1 é descrita abaixo:

- Definição do objetivo do estudo: Nesta etapa foi definido o local onde o trabalho seria realizado, além da revisão bibliográfica para identificação das melhores técnicas a serem aplicadas e consulta da legislação aplicável para atender as normas de segurança necessárias;

- Recolhimento de informações: Foram realizadas entrevistas com os colabores e visitas e in loco para a elaboração do mapa de risco, sendo que segundo Chiroli et al. (2019) para a elaboração do mapa de risco deve-se analisar o local a fim de conhecer o ambiente e identificar os riscos, além disso, devem ser realizadas entrevistas com os colaboradores sobre a situação dos equipamentos de proteção, as atividades desenvolvidas e os riscos de acidentes; 
- Aplicação das metodologias FMEA e SLP: Nesta etapa, foram seguidos os passos já descritos no referencial teórico para elaboração dos layouts mais adequados ao laboratório;

- Discussão dos resultados e considerações finais: Foi escolhido e analisado o melhor layout para o local.

Logo, esse artigo produziu um documento com boas práticas de manutenção que deverá ser revisto sempre que necessário, levando em consideração alterações no ambiente, conforme o planejamento simplificado do layout, de forma que assegure padrões de eficiência e eficácia para o melhor funcionamento do laboratório.

\section{CARACTERIZAÇÃO DO LOCAL DE ESTUDO}

O laboratório de polímeros e processos de transformações de materiais é uma unidade acadêmica de formação superior de um instituto público de geociências e engenharias, cujo objetivo é conciliar a sustentabilidade ambiental aos benefícios práticos dos polímeros. Suas atividades de pesquisa relacionam-se principalmente a Engenharia de Biocombustíveis: processos de produção e separação ou purificação de biocombustíveis (Biodiesel e Produto Líquido Orgânico/Bio-óleo), a partir das rotas tecnológicas de transesterificação (Catálise Homogênea) e craqueamento (Catálise Heterogênea) de diversas matériasprimas da região Amazônica (Dendê, Buriti, Andiroba, Tucumã, Castanha do Pará, Semente de Girassol), assim como materiais residuais (Óleo de Fritura, Sais de Ácidos Graxos e Sebo Bovino), com aplicação de catalisadores comerciais (Carbonato de Sódio, Carbonato de Cálcio, Sílica Suportada) e residuais (Lama Vermelha, Caulim Residual, Pó de Aciaria Elétrica-PAE), em diferentes escalas de produção (Bancada, Semi Piloto e Piloto), além de pesquisas voltadas a extração e caracterização de óleos vegetais.

Diante desse cenário, é essencial que haja o levantamento dos riscos ocupacionais assim como do melhor layout disposto ao laboratório, dessa forma, permitindo que o desempenho satisfatório nas atividades de ensino e pesquisa possibilite maiores parcerias com instituições de pesquisa e empresas privadas.

\section{RESULTADOS E DISCUSSÕES}

\section{IDENTIFICAÇÃO E AVALIAÇÃO DOS RISCOS AMBIENTAIS NO LABORATÓRIO}

As tarefas realizadas em laboratório pelos discentes resumem-se: na organização de vidrarias e do laboratório para a realização das aulas, na preparação de reagentes em diferentes concentrações, no armazenamento de reagentes e resíduos e na manutenção de equipamentos em alguns casos. Já os docentes dependem de fatores como a disciplina a ser ministrada e o tópico da aula de cada disciplina. Durante a entrevista, todos os entrevistados consideramse vulneráveis a acidentes durante as aulas e atividades no laboratório. Os discentes informaram que já presenciaram acidentes dentro do laboratório.

Logo, conforme Batalha (2012), a identificação dos riscos e a devida avaliação é essencial para garantir a segurança de todos os colaboradores, 
partindo desse conceito o Mapa de Risco ilustrado na Figura 2, identifica os riscos, assim como contribui na caracterização dos possíveis agentes causadores.

Figura 2 - Mapa de risco do laboratório de polímeros e processos de transformações de materiais

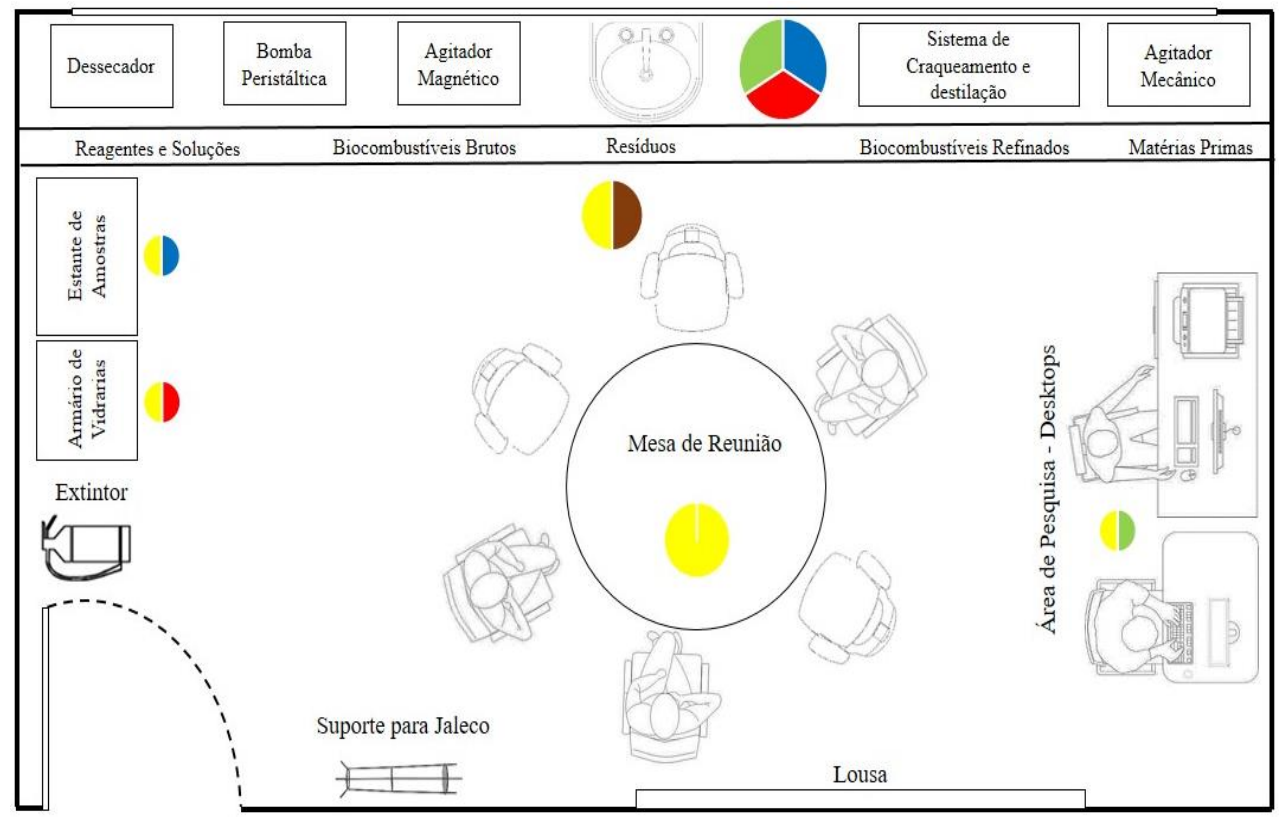

Fonte: Autoria própria (2019)

Conforme o layout do laboratório de polímeros e com o mapeamento de riscos, foram adotados os seguintes passos para a representação dos riscos proveniente ao local estudado, de acordo com Vieira (1998): 1을 conhecimento do processo de trabalho no local analisado, 20 identificação dos riscos existentes e 30 identificação das medidas preventivas.

Os riscos encontrados em cada setor analisado do laboratório estão representados nas Tabelas 1, 2 e 3. Logo pode-se observar a gravidade dos riscos de acordo com o tamanho dos círculos, em que o círculo grande tem um alto nível de risco, o círculo mediano possui um nível médio de risco e por fim o círculo pequeno com um nível baixo de risco ambiental. E ainda nas tabelas é notória a discussão das possíveis causas e as recomendações sugeridas para cada risco.

Tabela 1 - Causa e recomendações para os riscos de intensidade alto

\begin{tabular}{c|c|c|c}
\hline Simbologia & Nível & \multicolumn{2}{|c}{ Intensidade dos Riscos Ambientais - Círculo Grande } \\
\hline & & Causa & Risco Químico \\
\cline { 3 - 4 } & \multirow{2}{*}{$*$} & $\begin{array}{c}\text { Recomendações } \\
\text { Produtos químicos } \\
\text { em geral, } \\
\text { reagentes, } \\
\text { biocombustíveis e } \\
\text { resíduos químicos } \\
\text { que causam gases } \\
\text { e vapores. }\end{array}$ & $\begin{array}{c}\text { Para evitar os riscos químicos é } \\
\text { importante que haja medidas de } \\
\text { proteção individual, coletiva, } \\
\text { educativa e administrativas quanto ao } \\
\text { uso dos EPIs para que seja frequente, } \\
\text { e ainda é importante que haja a } \\
\text { devida manutenção dos } \\
\text { equipamentos de exaustão e }\end{array}$ \\
\hline
\end{tabular}




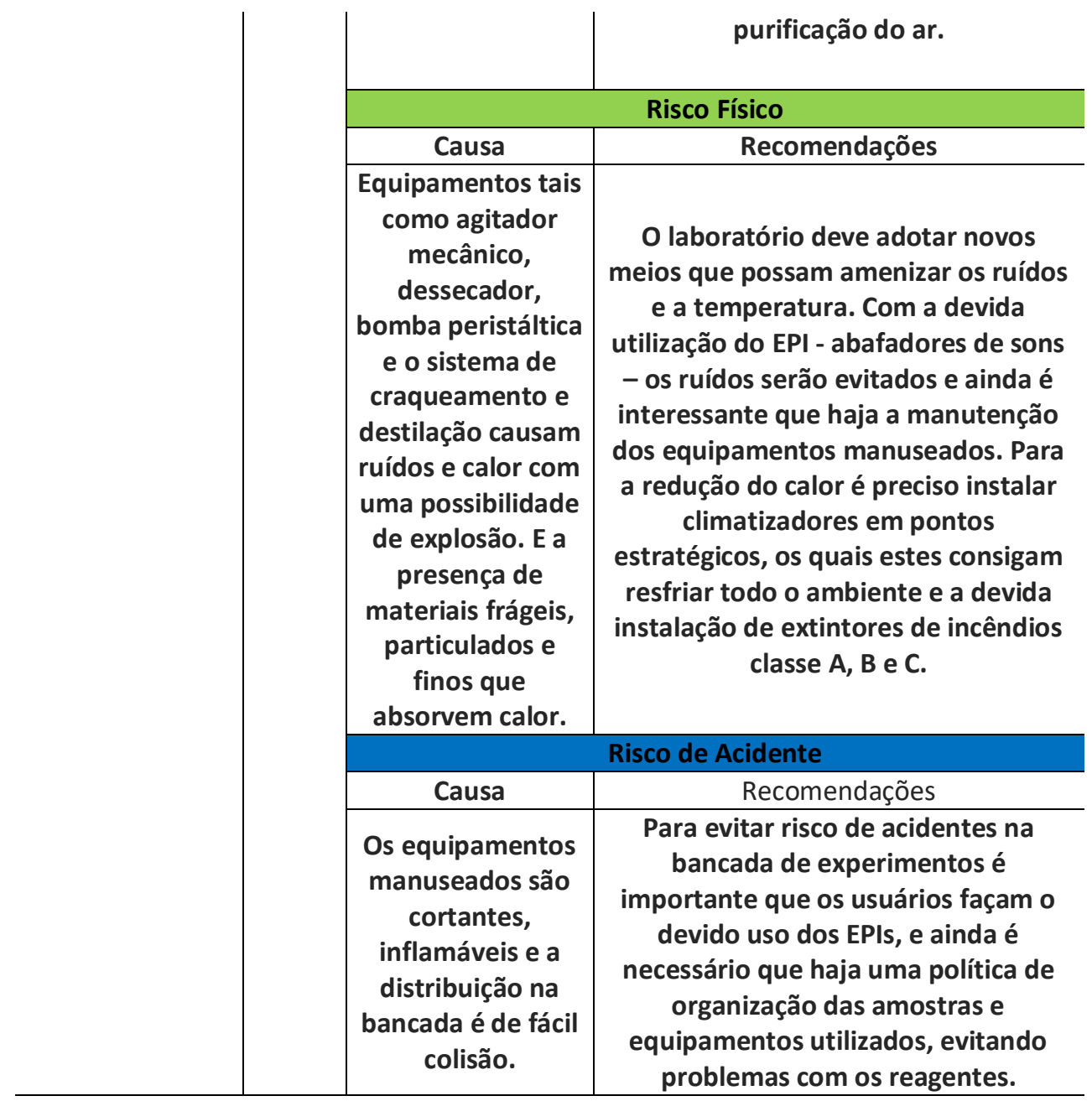

Fonte: Autoria própria (2019)

O ambiente ainda possui desconformidades, de acordo com a Norma regulamentadora 23. O ambiente apresenta uma saída apenas que é utilizada como entrada e saída do ambiente, e esta possui abertura para dentro do laboratório, dificultando a evacuação do local, entrando em discordância com o tópico 23.2 da NR. Além disso, os extintores presentes não se encontram instalados e sinalizados como estabelece o tópico 23.1.1 da NR. Conforme NR 7 em seu item 7.5.1, todo estabelecimento deverá estar equipado com materiais de prestação de primeiros socorros para atendimento emergencial em caso de acidente, e o laboratório não apresenta um kit de primeiros socorros.

Tabela 2 - Causa e recomendações para os riscos de intensidade médios

\begin{tabular}{|c|c|c|c|}
\hline Simbologia & Nível & \multicolumn{2}{|c|}{ Intensidade dos Riscos Ambientais - Círculo Mediano } \\
\hline & & \multicolumn{2}{|c|}{ Risco Ergonômico } \\
\hline & & Causa & Recomendações \\
\hline & $\frac{\frac{0}{9}}{\stackrel{0}{\frac{d}{2}}}$ & $\begin{array}{l}\text { Esforço repetitivo, postura } \\
\text { incorreta - devido a banqueta } \\
\text { e a posição dos produtos e } \\
\text { reagentes. Além disso, é } \\
\text { estressante a } \\
\text { responsabilidade devido ao } \\
\text { número de pessoas que } \\
\text { manuseiam os equipamentos }\end{array}$ & $\begin{array}{l}\text { É importante que os } \\
\text { discentes atenham-se na } \\
\text { inclinação de forma certa } \\
\text { para evitar a curvaturas na } \\
\text { coluna. Evitar movimentos } \\
\text { repentinos que produzam } \\
\text { tensões musculares, pois o } \\
\text { levantamento rápido dos }\end{array}$ \\
\hline
\end{tabular}




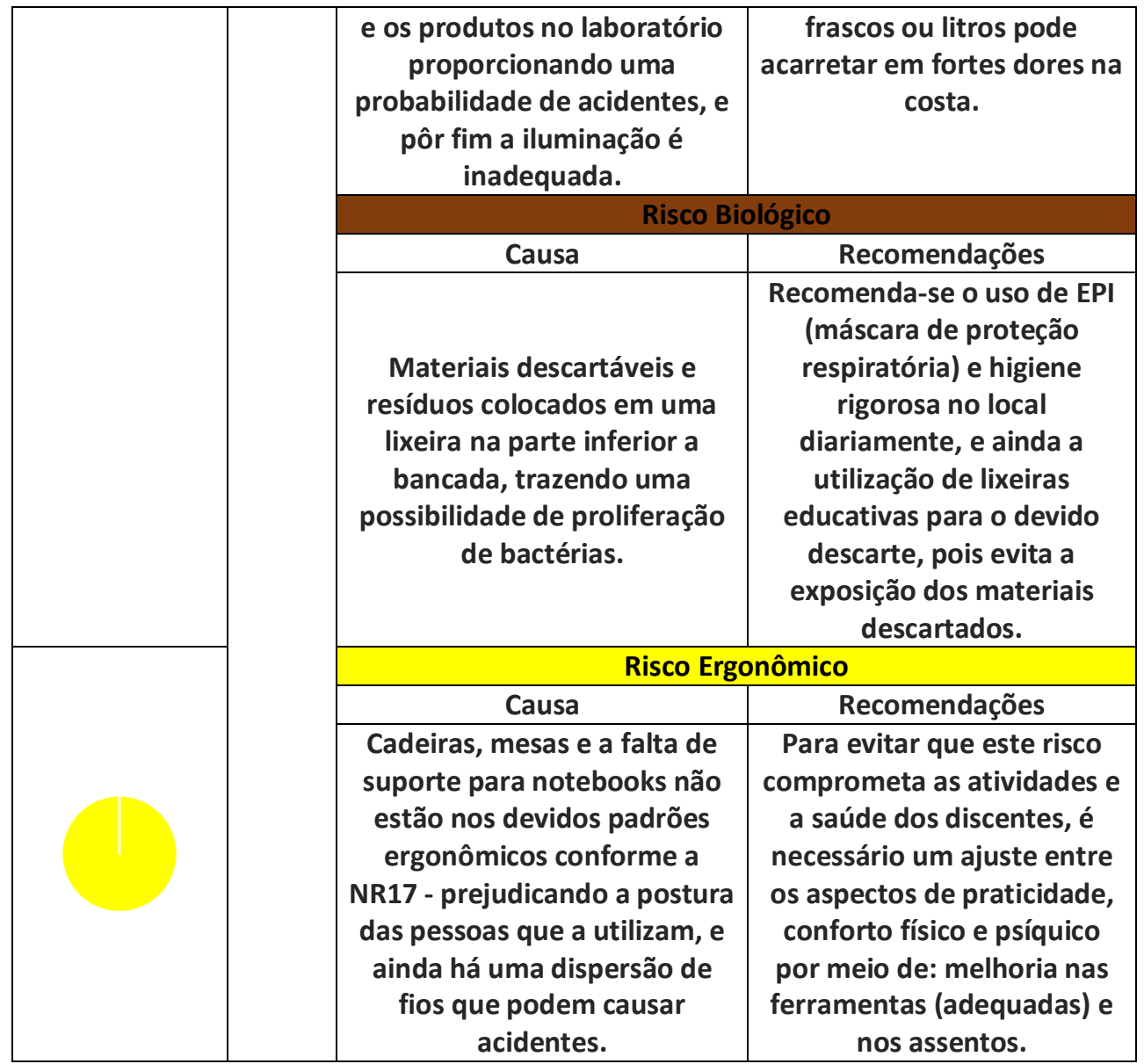

Fonte: Autoria própria (2019)

Observou-se ainda, que o ambiente em estudo contém mesas e cadeiras ergonomicamente incorretas, em desacordo a NR 17, item 17.5.1. Outro ponto notório, é que não são realizados exames periódicos de saúde dos funcionários que se expõem durante oito horas diárias às substâncias nocivas à saúde humana, e o PCMSO, se existe na instituição, não é aplicado, como determina a NR 7, no item 7.2.4. Constatou-se ainda, a desorganização do ambiente, onde os aparelhos e vidros contendo substâncias químicas utilizadas nas análises se encontram espalhados nas bancadas, não havendo um armazenamento adequado, como determina a NR 17, item 17.1.1.

Tabela 3 - Causa e recomendações para os riscos de intensidade baixos

\begin{tabular}{|c|c|c|c|}
\hline Simbologia & Nível & \multicolumn{2}{|c|}{ Intensidade dos Riscos Ambientais - Círculo Pequeno } \\
\hline & \multirow{5}{*}{ 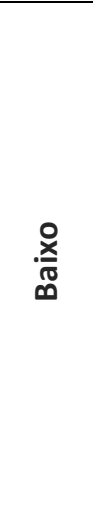 } & \multicolumn{2}{|c|}{ Risco Ergonômico } \\
\hline & & Causa & Recomendações \\
\hline & & $\begin{array}{l}\text { Esforço repetitivo e } \\
\text { postura incorreta - devido } \\
\text { a posição inadequada dos } \\
\text { equipamentos de medição, } \\
\text { aferição e outros no } \\
\text { armário de vidrarias. }\end{array}$ & $\begin{array}{l}\text { É essencial que haja uma } \\
\text { organização das vidrarias no armário } \\
\text { de forma que possibilite o melhor } \\
\text { acesso e melhore a iluminação } \\
\text { presente no local. Ainda é } \\
\text { importante que os discentes evitem } \\
\text { movimentos repentinos que } \\
\text { produzam tensões musculares. }\end{array}$ \\
\hline & & \multicolumn{2}{|c|}{ Risco de Acidente } \\
\hline & & Causa & Recomendações \\
\hline
\end{tabular}




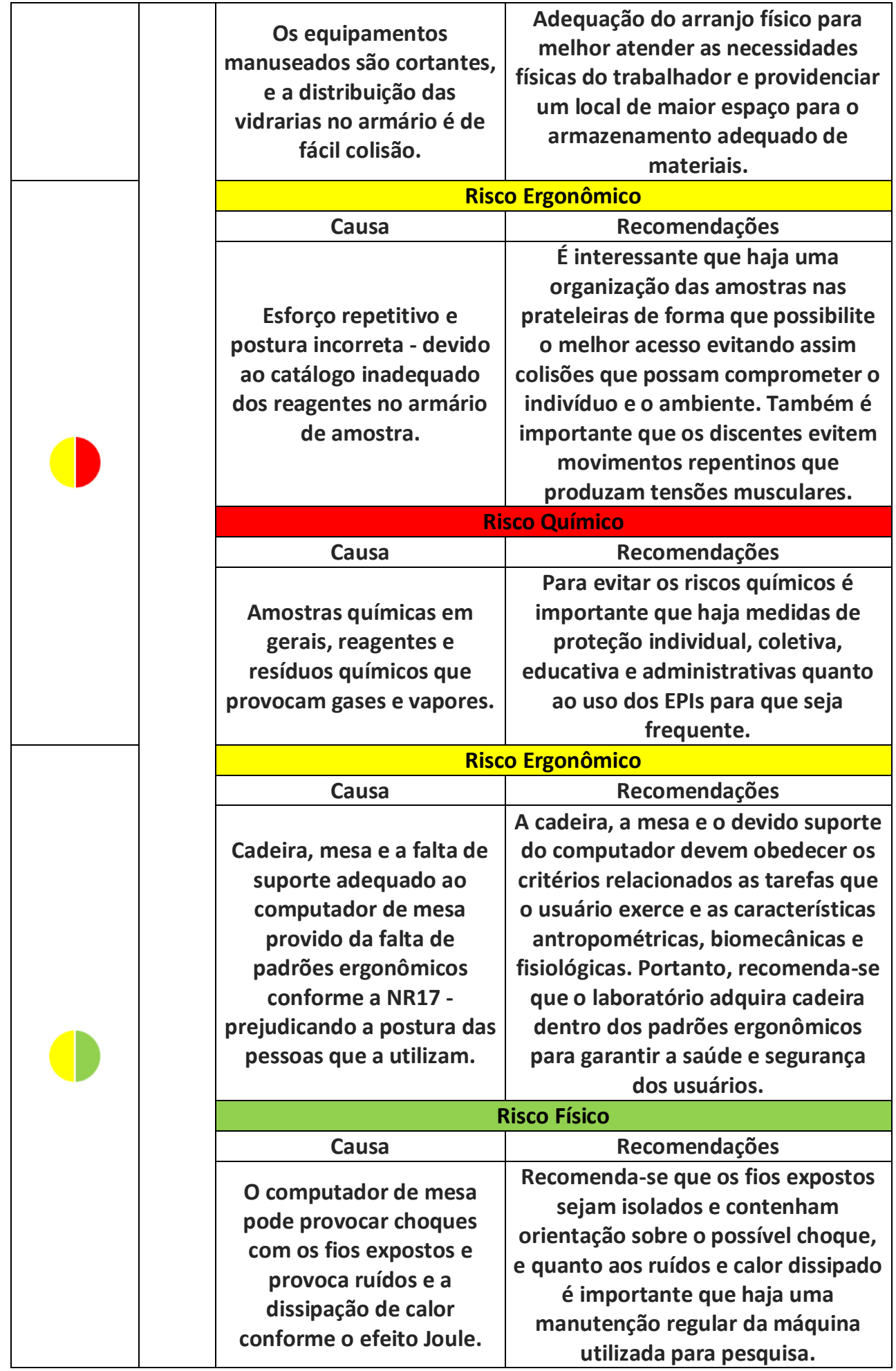

Fonte: Autoria própria (2019).

Nas medidas de controle organizacionais, notou-se que conforme a NR 26 em seu item 26.2.3.4, os produtos químicos necessários à realização das análises não possuem FISPQ - Ficha de Informação de Segurança de Produtos Químicos. 


\section{APLICAÇÃO DO FMEA NO LABORATÓRIO}

Pode-se afirmar que uma investigação mais aprofundada sobre a segurança do ambiente de trabalho faz com que as pessoas responsáveis pelo laboratório tenham a real percepção da necessidade da utilização de modelos de deteç̧ão e avaliação de riscos ocupacionais. Então, o FMEA foi constituído com o intuito de garantir uma maior confiabilidade para os processos realizados no laboratório, assim o levantamento dos dados juntamente com os pontos de Severidade (S), Ocorrência (P), Detecção (D), foram obtidos com o auxílio dos dois discentes que utilizam o laboratório para as atividades de pesquisa. Com base nestes dados, foi possível calcular qual era o RPN para cada um dos riscos potenciais. A Tabela 4 apresenta o RPN para cada risco identificado. Sendo assim, a equipe foi capaz de determinar quais seriam os riscos potenciais e como deveriam ser tomadas ações em um primeiro momento, a fim de garantir a qualidade dos processos e confiabilidade no laboratório.

Tabela 4 - FMEA - Análise dos modos de falhas e seus efeitos

\begin{tabular}{|c|c|c|c|c|c|c|c|c|}
\hline $\begin{array}{l}\text { Proce } \\
\text { sso }\end{array}$ & $\begin{array}{c}\text { Risco } \\
\text { Potencial }\end{array}$ & Efeitos & $S$ & Causas & 0 & Controle & D & RPN \\
\hline \multirow{8}{*}{ 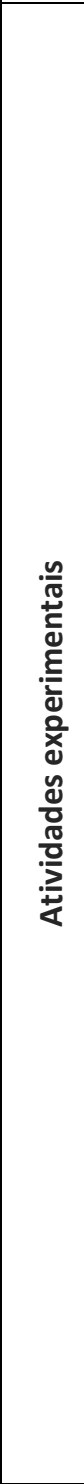 } & \multirow{7}{*}{$\begin{array}{l}\text { Vazamen } \\
\text { to de } \\
\text { substânci } \\
\text { as } \\
\text { químicas }\end{array}$} & \multirow{3}{*}{$\begin{array}{l}\text { Lesão na parte do } \\
\text { corpo que entrou } \\
\text { em contato com a } \\
\text { substância }\end{array}$} & 9 & $\begin{array}{l}\text { Recipientes } \\
\text { danificado }\end{array}$ & 8 & \begin{tabular}{|c|} 
Inspecionar os \\
recipientes antes \\
de utilizá-los
\end{tabular} & 1 & 72 \\
\hline & & & 9 & $\begin{array}{l}\text { Vestimenta } \\
\text { inadequada }\end{array}$ & 7 & Utilizar EPI's & 1 & 63 \\
\hline & & & 9 & $\begin{array}{c}\text { Operação } \\
\text { indevida com } \\
\text { substâncias } \\
\text { químicas } \\
\end{array}$ & 9 & $\begin{array}{c}\text { Falta de } \\
\text { conhecimento }\end{array}$ & 3 & 243 \\
\hline & & $\begin{array}{c}\text { Danificar } \\
\text { estrutura física } \\
\text { do ambiente ou } \\
\text { itens que o } \\
\text { compõem }\end{array}$ & 7 & $\begin{array}{c}\text { Realizar } \\
\text { manuseio de } \\
\text { substâncias } \\
\text { químicas em local } \\
\text { inadequado }\end{array}$ & 10 & \begin{tabular}{|c} 
Realizar \\
experimentos no \\
balcão \\
disponibilizado
\end{tabular} & 2 & 140 \\
\hline & & \multirow{3}{*}{$\begin{array}{l}\text { Princípio de } \\
\text { incêndio ou } \\
\text { explosão }\end{array}$} & 10 & $\begin{array}{c}\text { Armazenamento } \\
\text { impróprio }\end{array}$ & 9 & $\begin{array}{l}\text { Disponibilizar um } \\
\text { local para } \\
\text { armazenagem } \\
\text { dos produtos } \\
\text { utilizados com as } \\
\text { recomendações } \\
\text { como bacia de } \\
\text { contenção e etc. }\end{array}$ & 2 & 180 \\
\hline & & & 10 & \begin{tabular}{|c|} 
Contato ou \\
proximidade das \\
substâncias \\
inflamáveis com \\
aquecedores ou outras \\
substâncias que \\
provocam uma reação \\
\end{tabular} & 10 & \multirow{2}{*}{$\begin{array}{l}\text { Trabalhos com líquidos } \\
\text { inflamáveis voláteis } \\
\text { devem ser realizados } \\
\text { em capelas com } \\
\text { sistema elétrico à } \\
\text { prova de explosão. }\end{array}$} & 1 & 100 \\
\hline & & & 10 & \begin{tabular}{|c|} 
Operação \\
indevida com \\
substâncias \\
químicas \\
\end{tabular} & 7 & & 1 & 70 \\
\hline & \begin{tabular}{|c|} 
Acidente \\
s com \\
equipam
\end{tabular} & Choque & 8 & $\begin{array}{c}\text { Fios } \\
\text { desencapados } \\
\text { ocasionando } \\
\end{array}$ & 8 & $\begin{array}{l}\text { Manutenção do } \\
\text { sistema elétrico }\end{array}$ & 2 & 128 \\
\hline
\end{tabular}




\begin{tabular}{|c|c|c|c|c|c|c|c|}
\hline \multirow[t]{4}{*}{\begin{tabular}{|l} 
entos \\
elétricos
\end{tabular}} & & & $\begin{array}{c}\text { choques elétricos } \\
\begin{array}{c}\text { ou curtos- } \\
\text { circuitos }\end{array} \\
\end{array}$ & & & & \\
\hline & & 8 & $\begin{array}{c}\text { Fuga de corrente } \\
\text { elétrica }\end{array}$ & 6 & $\begin{array}{l}\text { Instalar DR } \\
\text { (Diferencial } \\
\text { Residual) no } \\
\text { sistema de } \\
\text { aterramento }\end{array}$ & 3 & 144 \\
\hline & & 9 & $\begin{array}{l}\text { Fazer reparos em } \\
\text { instrumentos sem } \\
\text { desconectar da } \\
\text { rede elétrica }\end{array}$ & 7 & \begin{tabular}{|c} 
Desligar \\
equipamentos \\
quando terminar \\
de utilizar ou for \\
realizar algum \\
reparo \\
\end{tabular} & 1 & 63 \\
\hline & $\begin{array}{l}\text { Princípio de } \\
\text { incêndio ou } \\
\text { explosão }\end{array}$ & 8 & $\begin{array}{l}\text { Conectar vários } \\
\text { aparelhos em } \\
\text { uma mesma } \\
\text { tomada }\end{array}$ & 9 & \begin{tabular}{|c} 
Os \\
equipamentos, \\
bem como as \\
tomadas \\
elétricas, devem \\
ser à prova de \\
explosão.
\end{tabular} & 2 & 144 \\
\hline $\begin{array}{l}\text { Acidente } \\
\text { s com } \\
\text { vidrarias } \\
\text { e } \\
\text { materiais }\end{array}$ & Ferimentos & 9 & $\begin{array}{l}\text { Transporte } \\
\text { inapropriado }\end{array}$ & 8 & $\begin{array}{c}\text { Utilizar algum } \\
\text { suporte sempre } \\
\text { que for } \\
\text { transportar } \\
\text { algum recipiente }\end{array}$ & 1 & 72 \\
\hline $\begin{array}{c}\text { cortantes } \\
\text { e } \\
\text { contunde } \\
\text { ntes }\end{array}$ & $\begin{array}{l}\text { Despesas para } \\
\text { reposição de } \\
\text { materiais }\end{array}$ & 5 & $\begin{array}{l}\text { Recipientes } \\
\text { danificados }\end{array}$ & 9 & $\begin{array}{c}\text { Ao receber } \\
\text { recipientes novos } \\
\text { verificar se estão } \\
\text { danificados }\end{array}$ & 1 & 45 \\
\hline
\end{tabular}

Fonte: Autoria própria (2019)

Analisando a tabela com os resultados do FMEA, notou-se que foram aplicados três tipos de riscos potenciais diferentes. Para cada modo de risco, foram analisados os efeitos e classificados conforme a metodologia FMEA, ou seja, lesões por entrar em contato com alguma substância têm como causa recipientes danificadas com um RPN de setenta e dois, vestimentas inadequadas utilizadas pelos usuários do laboratório com um RPN de sessenta e três, e operação indevida com substâncias químicas com o maior RPN de duzentos e quarenta e três. Ainda, tendo como risco potencial vazamento de substâncias químicas, na segunda situação nota-se que o efeito é o de danificar estrutura física do ambiente ou itens que fazem parte do mesmo, contudo, tendo agora como causa a realização e manuseio de substâncias químicas em local inadequado, o que gerou um RPN de cento e quarenta. E por fim com o mesmo risco, porém com um efeito de incêndio ou explosão que são causados por armazenamento impróprio com um RPN de cento e oitenta, contatos ou proximidade das substâncias inflamáveis com aquecedores ou outras substâncias que provocam uma reação com um RPN de cem e operação indevida com substâncias químicas com um RPN de setenta. Na segunda situação, tendo como risco potencial, acidentes com equipamentos elétricos com o efeito de choque cujas possíveis causas são: fios desencapados ocasionando choques elétricos ou curtos-circuitos com o RPN gerado de cento e vinte e oito, fuga de corrente elétrica com um RPN de cento e quarenta e quatro e fazer reparos em 
instrumentos sem desconectar da rede elétrica com o RPN gerado de sessenta e três. Ainda, com o mesmo risco potencial, nota-se que um efeito de princípio de incêndio ou explosão é recorrente, contudo, tendo agora como causa a conexão de vários aparelhos em uma mesma tomada o que gerou um RPN de cento e quarenta e quatro. E por fim a terceira situação, tendo como risco potencial, acidentes com vidrarias e materiais cortantes e contundentes com efeito de ferimentos e despesas para reposição de materiais, causados assim por transportes inapropriados com RPN de setenta e dois, e despesas para reposição de materiais com RPN de quarenta e cinco respectivamente. Então é perceptível que para um mesmo risco em potencial, existem diferentes valores de RPN. Esta diferença de valor reside apenas pelo fato dos efeitos serem diferentes, e por consequência o índice de gravidade também é diferente. Entende-se que se deve atuar nas causas que tenha o índice de gravidade mais elevado. Deste modo, o planejamento simplificado de layout (SLP) foi desenvolvido com o intuito de trazer ações corretivas para os riscos potenciais discutidos na análise do FMEA.

\section{ETAPAS DO PLANEJAMENTO SIMPLIFICADO DE LAYOUT (SLP)}

\section{Diagrama de Relações}

A partir das visitas realizadas e das entrevistas, foi possível relacionar os postos de trabalho e determinar as proximidades relativas entre os mesmos no processo, no entanto, os equipamentos dispostos na bancada de experimentos não entraram no estudo do SLP, pois conforme o coordenador e os discentes do laboratório os equipamentos estão dispostos devidamente para a realização dos procedimentos, assim o diagrama de relação segue conforme a Figura 3.

Figura 3 - Diagrama de Relações

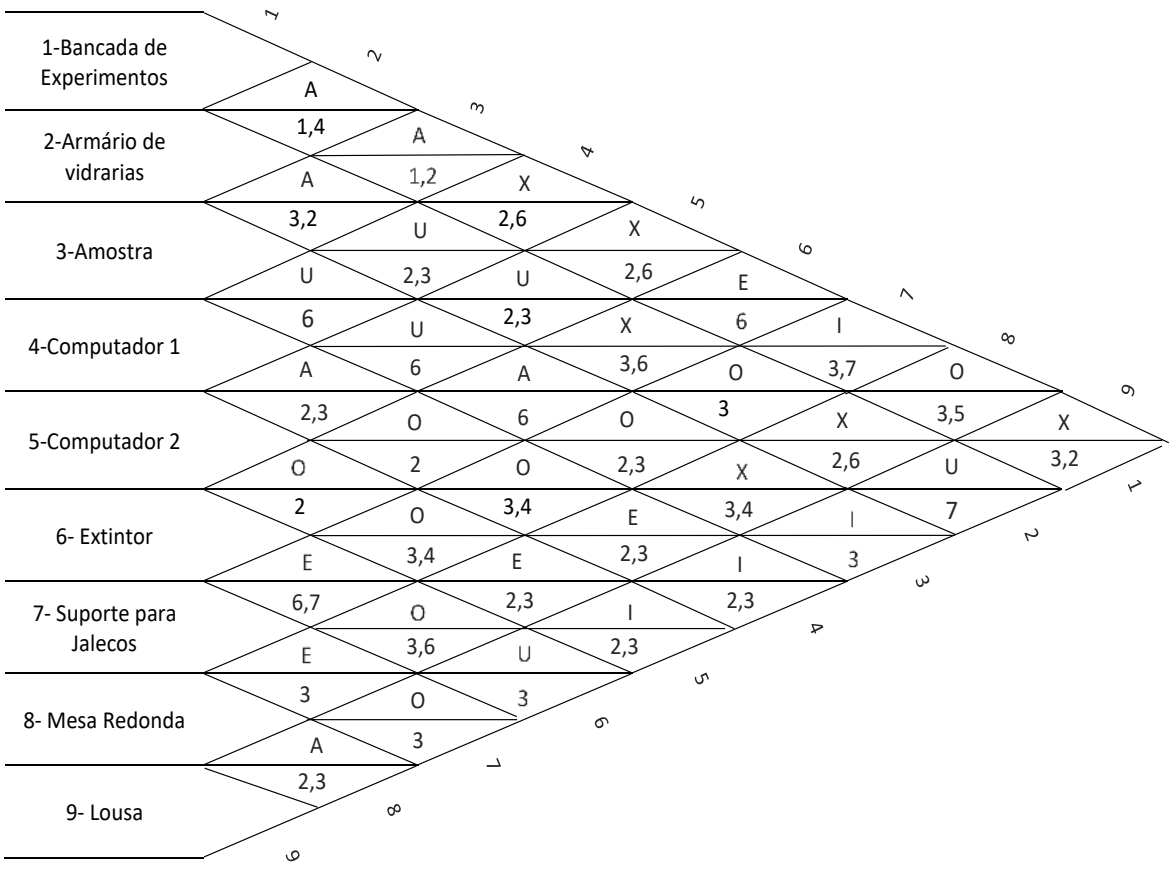

Fonte: Autoria própria (2019). 
A apresentação do diagrama das relações, na Figura 3, foi elaborada através de uma matriz em forma triangular que auxiliou na determinação da proximidade relativa entre cada área com os seus devidos equipamentos que estão envolvidos no layout do laboratório, onde foram listadas as atividades e atribuídos os valores de proximidades entre elas a fim de se reduzir movimentação indevida. $\mathrm{Na}$ Tabela 5, tem-se as legendas do grau de proximidade e as razões utilizadas no diagrama de relação.

Tabela 5 - Legendas dos símbolos utilizados no diagrama de relação

\begin{tabular}{|c|c|c|c|c|c|c|}
\hline \multirow{8}{*}{$\begin{array}{l}\frac{0}{0} \\
\frac{\pi}{0} \\
\frac{0}{0} \\
\frac{1}{x} \\
\frac{0}{2} \\
\frac{0}{0} \\
\frac{0}{0} \\
\frac{\pi}{0}\end{array}$} & Código & Proximidades & $\begin{array}{l}\text { № de } \\
\text { Classes }\end{array}$ & \multirow{8}{*}{ 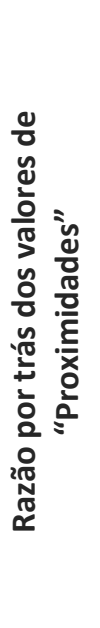 } & Valor & Razão \\
\hline & A & $\begin{array}{l}\text { Absolutamente } \\
\text { necessário }\end{array}$ & 6 & & 1 & $\begin{array}{l}\text { Movimentação } \\
\text { de materiais }\end{array}$ \\
\hline & E & $\begin{array}{l}\text { Especialmente } \\
\text { importante }\end{array}$ & 5 & & 2 & $\begin{array}{c}\text { Proximidade de } \\
\text { operações }\end{array}$ \\
\hline & 1 & Importante & 4 & & 3 & Uso em comum \\
\hline & 0 & Proximidade normal & 8 & & 4 & $\begin{array}{l}\text { Supervisão e/ou } \\
\text { suporte }\end{array}$ \\
\hline & u & Sem importância & 6 & & 5 & $\begin{array}{c}\text { Controle do } \\
\text { serviço }\end{array}$ \\
\hline & $\mathrm{x}$ & Não desejável & 6 & & 6 & $\begin{array}{l}\text { Prevenção de } \\
\text { acidentes }\end{array}$ \\
\hline & & Total & 35 & & 7 & $\begin{array}{c}\text { Conveniência } \\
\text { pessoal }\end{array}$ \\
\hline
\end{tabular}

Fonte: Autoria própria (2019)

\section{Estabelecimento da Necessidade de Espaço}

Para estabelecer as necessidades de espaço serão utilizadas as mesmas atividades listadas na seção anterior, onde será verificado e estabelecido a área necessária para cada atividade, e com isso se terá uma boa organização do espaço por atividades. Essa análise está representada na Tabela 6.

Tabela 6 - Análise das necessidades físicas

\begin{tabular}{|c|c|c|c|c|c|c|c|}
\hline Nome & $\begin{array}{c}\text { Área } \\
\left(\mathrm{m}^{2}\right)\end{array}$ & $\begin{array}{c}\text { Energia } \\
\text { Elétrica }\end{array}$ & Iluminação & $\begin{array}{c}\text { Conexão } \\
\text { de Rede }\end{array}$ & Água & $\begin{array}{c}\text { Perigo } \\
\text { de } \\
\text { incêndio } \\
\text { ou } \\
\text { explosão }\end{array}$ \\
\hline 1 & $\begin{array}{c}\text { Bancada de } \\
\text { Experimentos }\end{array}$ & 7,8 & I & O & - & A & A \\
\hline 2 & $\begin{array}{c}\text { Armário de } \\
\text { vidrarias }\end{array}$ & 2,0 & - & I & - & - & - \\
\hline 3 & Amostra & 1,0 & - & I & - & - & A \\
\hline 4 & $\begin{array}{c}\text { Computador } \\
1\end{array}$ & 0,85 & A & O & A & - & - \\
\hline 5 & $\begin{array}{c}\text { Computador } \\
2\end{array}$ & 0,85 & A & O & A & - & - \\
\hline 6 & Extintor & 1,0 & - & - & - & - & 0 \\
\hline 7 & $\begin{array}{c}\text { Suporte para } \\
\text { Jalecos }\end{array}$ & 1,5 & - & - & - & - & 0 \\
\hline 8 & Mesa & 2,8 & A & E & - & - & - \\
\hline
\end{tabular}




\begin{tabular}{|c|c|c|c|c|c|c|c|}
\hline & Redonda & & & & & & \\
\hline 9 & Lousa & - & - & I & - & - & - \\
\hline
\end{tabular}

Fonte: Autoria própria (2019)

Onde:

A = Absolutamente Necessário;

$\mathrm{E}=$ Especialmente Importante;

I = Importante;

$\mathrm{O}=$ Proximidade Normal;

- = Não Exigido.

Através da verificação das características das áreas e atividade do laboratório de polímeros e processos de transformações de materiais, observou-se que a energia elétrica é absolutamente necessária para a maioria dos equipamentos do ambiente, a água é uma exclusividade da bancada, e a iluminação tem uma importância também em praticamente todos os equipamentos. A área do local é de $24 \mathrm{~m}^{2}$, portanto há uma limitação em relação ao espaço, pois é um local pequeno e que suporta somente o necessário para as atividades, logo se percebe que a área ocupada é de $17,8 \mathrm{~m}^{2}$, ou seja, há um espaço pequeno para o desenvolvimento dos fluxos dos processos e materiais.

\section{Diagrama de Relacionamento das Atividades}

Após relacionar os postos de trabalho e suas necessidades foi possível esquematizar um provável arranjo para o espaço de uma forma mais objetiva e melhor disposta utilizando símbolos para representar os postos de trabalho e código de linhas o grau de proximidade entre eles de acordo com a Figura 4.

Figura 4 - Fluxo do diagrama de relação do laboratório

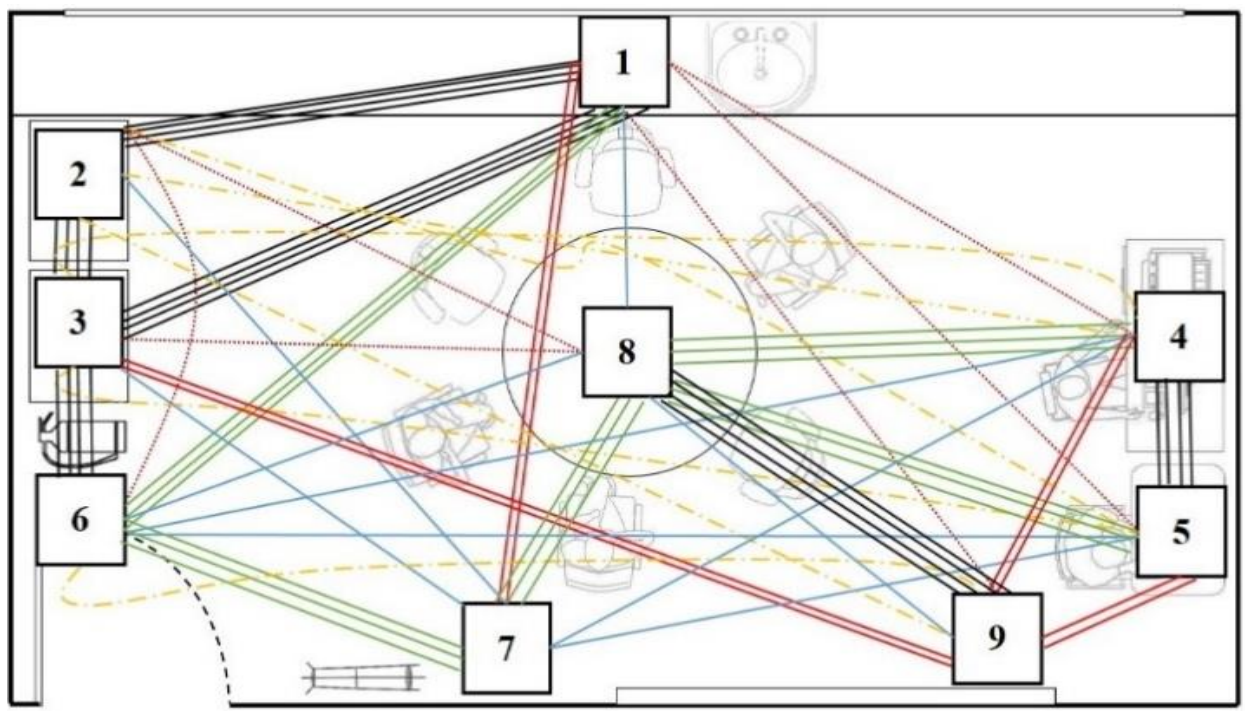




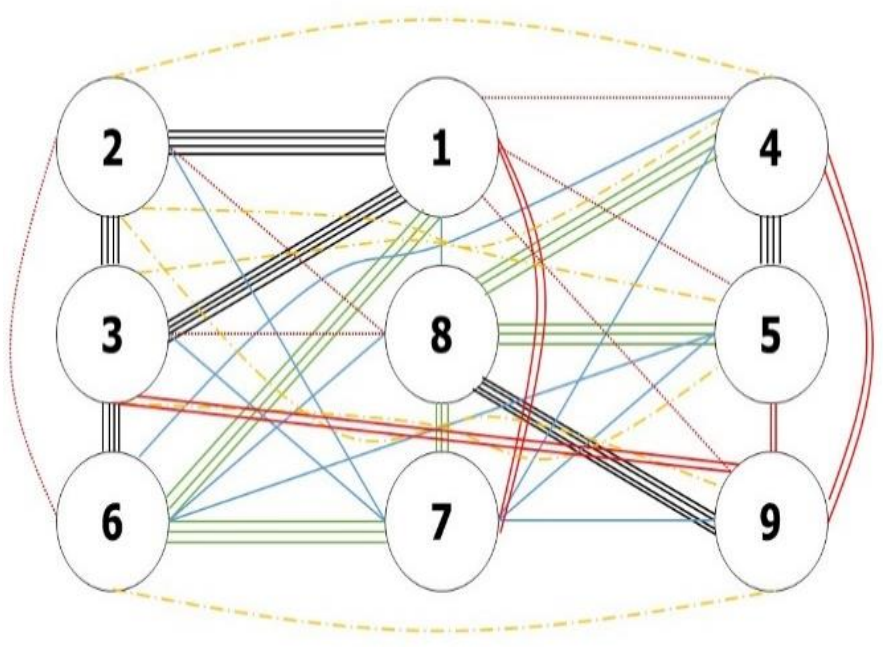

\begin{tabular}{|c|c|}
\hline Legenda & Grau de Proximidade \\
\hline$\overline{\overline{\underline{\underline{E}}}}$ & A \\
\hline$\overline{\bar{\equiv}}$ & $\mathrm{E}$ \\
\hline$=$ & I \\
\hline$\longrightarrow$ & $\mathrm{O}$ \\
\hline$-\cdot-\cdot-$ & $\mathrm{U}$ \\
\hline$\ldots \ldots \ldots \ldots \ldots \ldots \ldots$ & X \\
\hline
\end{tabular}

Fonte: Autoria própria (2019)

Então foi possível através do diagrama visual, demonstrado na Figura 4, visualizar o melhor arranjo físico, ou seja, nele as atividades se relacionam para gerar os resultados graficamente e visualmente resultando na formação básica do melhor layout.

\section{Apresentação dos Layouts Propostos}

Posterior à elaboração das etapas anteriores, deve-se projetar alternativas de layout, viabilizando as restrições e atributos encontrados. A partir disso, encontram-se nas Figuras 5 e 6, duas alternativas de layout para o laboratório de pesquisa, sendo que somente a bancada de experimentos manteve a disposição dos equipamentos em conformidade ao layout original, pois é necessária para a realização dos procedimentos adequadamente. 
Figura 5 - Primeiro layout proposto

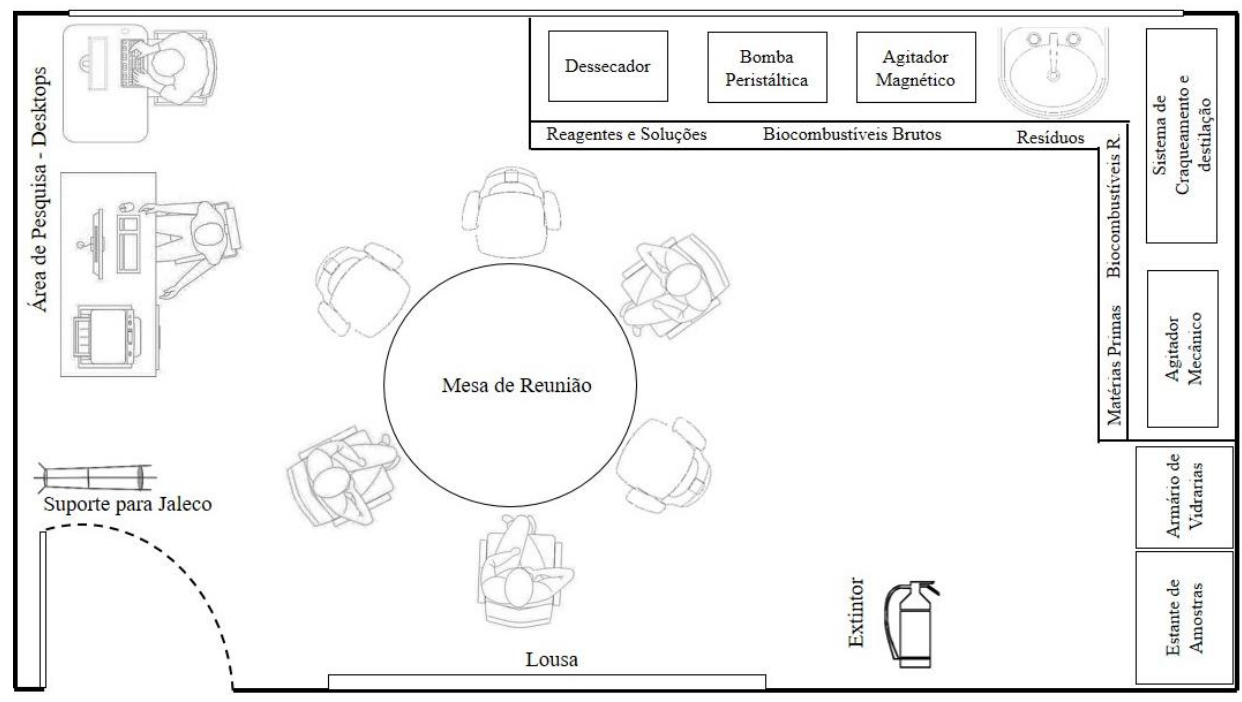

Fonte: Autoria própria (2019).

Na segunda proposta de layout - Figura 6 - também foram levados em consideração alguns fatores indicados pela literatura e escolhido juntamente com os discentes e o docente responsável do laboratório qual os mais relevantes para o arranjo físico.

Figura 6 - Segundo layout proposto

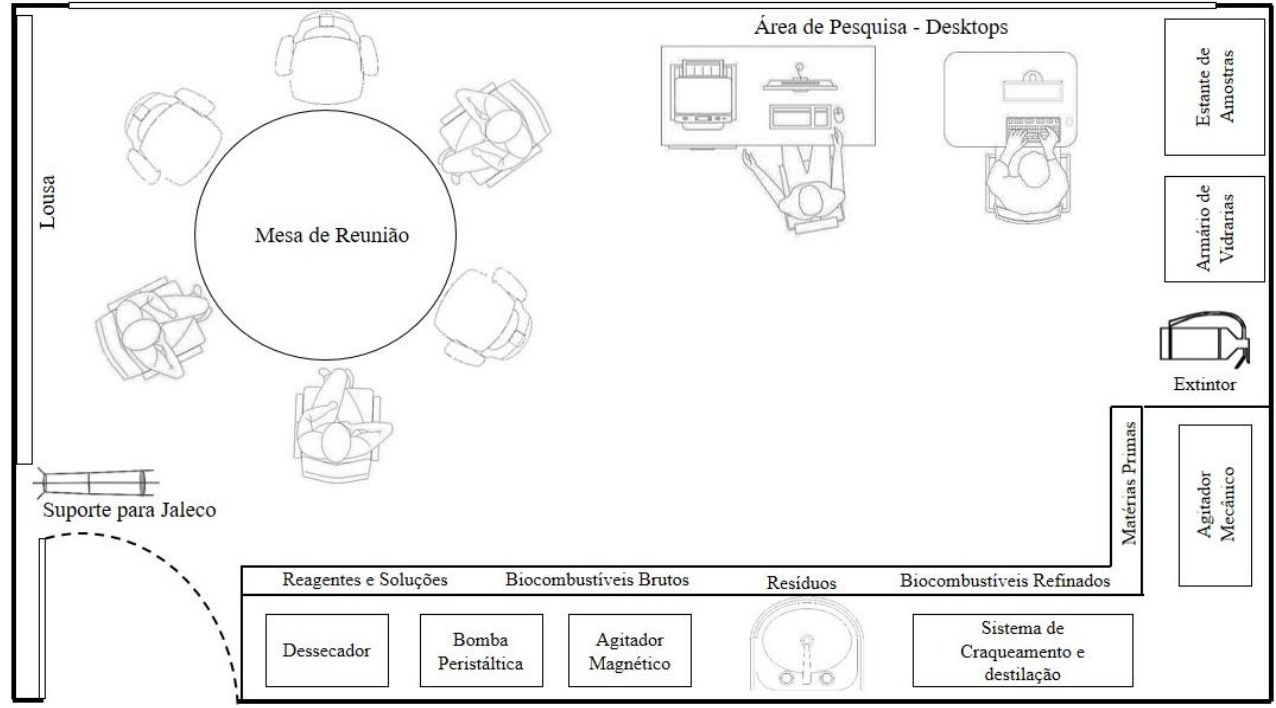

Fonte: Autoria própria (2019).

As principais modificações feitas na primeira proposta são:

- A bancada teve um pequeno ajuste de posição visando o aumento de espaço livre, para que houvesse a melhor movimentação dos usuários do laboratório;

- Os armários e a estante de amostra mudaram de localização favorecendo o fluxo de materiais; 
- Com o estudo de arranjo físico analisou-se que essa proposta de layout reduziu o cruzamento de fluxo de materiais, devido a nova disposição dos equipamentos no laboratório;

- O suporte de jalecos foi colocado em uma posição estratégica evidenciando aos usuários do laboratório a importância da utilização do jaleco no ambiente;

- O extintor foi colocado em um local estratégico, onde há um maior indício de acidentes com fogo.

Então, as modificações consideradas na segunda proposta são:

- A bancada também foi mudada de posição, porém totalmente, visando assim o aumento de espaço com o intuito de melhorar a movimentação dos usuários do laboratório;

- Alguns equipamentos foram mudados de localização conforme suas proximidades de acordo com os diagramas de inter-relações;

- A área de pesquisa assim como a lousa e a mesa de reunião foram realocados visando a diminuição da incidência de luz proveniente do sol pela janela;

- Os armários e a estante de amostra também mudaram de localização favorecendo o fluxo de materiais;

- O ambiente tornou-se mais organizado, e seguiu critérios ergonômicos;

- O suporte de jalecos continuou na mesma posição estratégica evidenciando aos usuários do laboratório a importância da utilização do jaleco no ambiente;

- O extintor também seguiu a estratégia de onde há um maior indício de acidentes com fogo;

- O layout foi organizado de acordo com a sequência do processo realizado pelos discentes e docentes para evitar movimentos desnecessários e otimizar o espaço.

\section{Escolha do Layout}

Após a seleção do melhor arranjo físico a partir das etapas anteriores, foi feito um novo esboço do plano de layout, agora em uma escala apropriada, identificando as principais áreas, características e detalhes significativos para a correta instalação dos equipamentos e organização do espaço, alcançando assim a melhoria do layout do laboratório. Para realizar a escolha do layout foram selecionados fatores principais e para cada um definiu-se um peso através da análise dos autores. O total de pontos é definido através da soma, da multiplicação das notas com os pesos como mostra a Tabela 7.

Tabela 7 - Seleção de layout

\begin{tabular}{|c|c|c|c|c|c|}
\hline \multicolumn{6}{|c|}{ Avaliação dos arranjos alternativos de layout do laboratório de pesquisa } \\
\hline \multirow{2}{*}{ Fator/consideração } & \multirow{2}{*}{ Peso } & \multicolumn{3}{c|}{ Pesos e classificações } \\
\cline { 3 - 6 } & & $\begin{array}{c}\text { Layout } \\
\text { inicial }\end{array}$ & $\begin{array}{c}\text { Proposta } \\
\mathbf{0 1}\end{array}$ & $\begin{array}{c}\text { Proposta } \\
\mathbf{0 2}\end{array}$ \\
\hline 1 & $\begin{array}{c}\text { Aproximação das } \\
\text { áreas por relação }\end{array}$ & 10 & $\begin{array}{l}\mathrm{E} \\
30\end{array}$ & $\begin{array}{c}\mathrm{E} \\
30\end{array}$ & \\
\hline
\end{tabular}




\begin{tabular}{|c|c|c|c|c|c|}
\hline 2 & Custo da mudança & 6 & 0 & $\mathrm{E}$ & $\begin{array}{l}\mathrm{E} \\
18\end{array}$ \\
\hline 3 & $\begin{array}{l}\text { Facilidade de } \\
\text { controle e } \\
\text { supervisão }\end{array}$ & 7 & & & \\
\hline 4 & $\begin{array}{c}\text { Diminui o } \\
\text { deslocamento }\end{array}$ & 10 & & & \\
\hline 5 & $\begin{array}{l}\text { Eficiência de } \\
\text { utilização dos } \\
\text { espaços }\end{array}$ & 8 & & & \\
\hline 6 & $\begin{array}{c}\text { Favorece o fluxo de } \\
\text { materiais }\end{array}$ & 7 & & & \\
\hline \multicolumn{3}{|c|}{ Totais } & 107 & 158 & 179 \\
\hline \multirow{4}{*}{\multicolumn{3}{|c|}{ Valores das Classificações }} & \multicolumn{2}{|c|}{ A (Quase Perfeito) } & 4 \\
\hline & & & \multicolumn{2}{|c|}{ E (Especialmente Bom) } & 3 \\
\hline & & & \multicolumn{2}{|c|}{$\begin{array}{l}\text { I (Resultados } \\
\text { Importantes) }\end{array}$} & 2 \\
\hline & & & \multicolumn{2}{|c|}{ O (Resultados Normais) } & 1 \\
\hline
\end{tabular}

Fonte: Autoria própria (2019)

A proposta 2 foi o layout escolhido, pois obteve a maior pontuação correspondente a 179 pontos. É visível que a proposta 2 proporciona aos usuários do laboratório uma maior mobilidade e uma facilidade no fluxo dos processos e dos materiais.

\section{CONSIDERAÇÕES FINAIS}

O estudo teve seu objetivo alcançado, primeiro que através do Mapa de Risco e com base nas Normas Regulamentadoras (NR) 05 e 09 do Ministério do Trabalho e Emprego foi possível identificar os riscos ocupacionais presentes no laboratório de polímeros e processos de transformações de materiais, o nível de gravidade dos mesmos e, por conseguinte determinar as possíveis causas e recomendações. E pode-se perceber que os riscos ergonômicos estão presentes na maior parte do ambiente, além disso, eles possuem problemas com armazenamento, manuseio e identificação dos produtos químicos que são responsáveis por riscos com maior gravidade. Além disso, a aplicação dessas ferramentas mostrou que a implantação de uma cultura de prevenção de acidentes no laboratório de polímeros e processos de transformações de materiais é essencial.

Em seguida a aplicação da ferramenta FMEA, muito utilizada para melhoria dos processos e organização de uma instituição, foi uma escolha certa, pois complementou o estudo ao possibilitar a identificação dos riscos potenciais dentro da principal atividade do laboratório que é a atividade experimental. Desta forma, mostrou através do resultado do RPN de cada causa destes riscos, qual se deve priorizar.

Para complementar, a aplicação do SLP foi essencial, pois o layout é uma das fontes dos riscos identificados. Portanto, essa ferramenta contribuiu na determinação do melhor layout, apresentando assim uma maior mobilidade e uma facilidade no fluxo dos processos e dos materiais, atuando no controle e eliminação dos principais riscos no laboratório. Assim, conclui-se que por meio 
deste estudo foi possível identificar o que e como deve ser melhorado. Desta forma, esta pesquisa apresenta grande relevância para a sociedade, pois mostra a preocupação com o bem-estar humano, e compartilha informações colaborando para um ambiente agradável aos usuários do espaço no centro universitário.

Como sugestão de trabalhos futuros, tem-se a aplicação dos conceitos de ergonomia no mobiliário, a fim de minimizar e/ou eliminar os riscos ergonômicos identificados no mapa de risco. 


\title{
The use of the FMEA and SLP methodology for prioritizing occupational risks: a case study in a research laboratory
}

\begin{abstract}
Brazilian legislation defines parameters and proposes methods that aim to guarantee health and safety at work. Among these methods is the mapping of accident risks. In this paper the application of the Failure Mode and Effects Analysis, model was analyzed, which, together with the risk map, provided essential information about the probability of occurrence of accidents and possible risk severities in a polymer laboratory and materials transformation processes, from a university center in the southeast of the state of Pará, in the municipality of Marabá. There was a detailed view of the processes of the studied environment, and with this, proposals for improvements to the layout were given through the application of the Systematic Layout Planning methodology. Therefore, the objective of this research was to analyze the conditions related to work safety, the availability of protective equipment, and also proposed a risk map model, a planned layout and a parameter of possible failures that can provide greater occupational rich, thus making professionals and academics working in the laboratory less vulnerable to accidents. After the SLP application, two layout proposals were elaborated, the second one was chosen due to better meeting the established criteria, besides improving the circulation space and the safety of the place.
\end{abstract}

KEYWORDS: SLP. FMEA. Risk map. Laboratory. 


\section{REFERÊNCIAS}

ANTÃO. M. L. Diagnóstico das condições de trabalho em altura e proposta de ferramentas de análise de risco. Recife, 2014, 152 p. Dissertação (Mestrado em Engenharia Civil) Escola Politécnica de Pernambuco. Universidade de Pernambuco.

BARBOZA, D V.; TEIXEIRA, M. A.; LIMA, G. B. A. Análise de riscos de um posto de combustíveis em Itaipuaçu utilizando a técnica HazOp.R. Gest. Industr, Ponta Grossa, v. 13, n. 2, p. 126-145, jun./ago. 2017. crossref

BATALHA, Ana. Identificação de Perigos e Avaliação de Riscos. In: Instituto Politécnico de Setúbal (IPS). Recife, 2012. Disponível em:

<https://comum.rcaap.pt/bitstream/10400.26/3882/1/Ana\%20Batalha\%20\%20Tr abalho\%20Final\%20SHT.pdf>. Acesso em: 08 jan. 2019.

CASOTTI, Rafael Ferreira; BATISTA, Bruna Campanharo; FREITAS, Rodrigo Randow de. Análise dos elos produtivos e aplicação do método de análise dos modos e efeitos de falhas (FMEA) na pesca artesanal no norte do Espírito Santo, Brasil. Revista Produção Online, Florianópolis, v. 17, n. 4, p. 1111-1133, dez. 2017. crossref

CHIAVENATO, Idalberto. Gestão de Pessoas: o novo papel dos recursos humanos nas organizações. Rio de Janeiro: Campus, 1999.

CAVALCANTI, Giseli Lopes Correia; LAGO, Eliane Maria Gorga; JUNIOR, Béda Barkokébas. Sistemática para análise de risco de saúde e segurança do trabalho em estações elevatórias de água. Revista Produção Online, Florianópolis, v. 17, n. 1, p. 108-132, mar. 2017. Disponível em: <https://www. producaoonline.org.br/rpo/article/view/2369>. Acesso em: 16 jan. 2019. crossref

CHIROLI, Daiane Maria de Genaro; CHRISTÓFORO, Letícia Coutinho; DESCHAMPS, Fernanda; SAKAKIBARA, Emy; BAÚ, Ana Caroline. Work safety management applied to a lab used by a junior company of chemical engineering. Independent Journal Of Management \& Production, v. 10, n. 1, p.281-300, 1 fev. 2019. crossref

Conselho regional de engenharia e segurança do trabalho do Rio de Janeiro. Cartilha de Segurança no Trabalho. Disponível em: <http://www.crearj.org.br/wpcontent/uploads/2012/08/cartilha_seguranca_do_trabalho_2013_WEB.pdf> Acesso em: 10 jan. 2019. 4. ed. Rio de Janeiro: 2013. 30 p. 
DE CASTRO, Tainara Rigotti; OKAWA, Cristhiane Passos. Auditoria de segurança e saúde do trabalho em uma indústria de alimentos do Estado do Paraná. Revista Produção Online, Florianópolis, v. 16, n. 2, p. 678-704, jun. 2016. Disponível em: <https://www.producaoonline.org.br/rpo/article/view/2063>. Acesso em: 16 jan. 2019. crossref

FAVONI, Célio; GAMBI, Lillian do Nascimento; CARETA, Catarina Barbosa. Oportunidades de implementação de conceitos e ferramentas de produção enxuta visando melhoria da competitividade de empresas do APL calçadista de Jaú/SP. Revista Produção Online, Florianópolis, v. 13, n. 3, p. 1118-1142, ago. 2013. crossref

Ministério do Trabalho e Emprego (MTE). Norma Regulamentadora no 5, de 12 de julho de 2011. Comissão Interna de Prevenção de Acidentes. Brasília, 14 jul. 2011. Disponível em:

<http://portal.mte.gov.br/data/files/8A7C812D311909DC0131678641482340/nr _05.pdf>. Acesso em: 05 jan. 2019.

MTE. Norma Regulamentadora no 7, de 09 de dezembro de 2013. Programa de Controle Médico de Saúde Ocupacional. Brasília, 11 dez. 2013. Disponível em: <http://portal.mte.gov.br/data/files/FF8080814295F16D0142E2E773847819/NR 07\%20(atualizada\%202013).pdf>. Acesso em: 10 jan. 2019.

MTE. Norma Regulamentadora no 9, de 24 de setembro de 2014. Programa de Prevenção de Riscos Ambientais. Brasília, 25 set. 2014. Disponível em: <http://portal.mte.gov.br/data/files/FF80808148EC2E5E014961B76D3533A2/NR09 (atualizada 2014) II.pdf>. Acesso em: 05 Set. 2018.

MTE, Segurança e saúde no trabalho. Disponível em: <http://trabalho.gov.br/ seguranca-e-saude-no-trabalho/normatizacao/normas-regulamentadoras $>$. Acesso em 17 Set. 2018.

MOREIRA, Herivelto; CALEFFE, Luiz G. Metodologia da pesquisa para o professor pesquisador. 2. ed. Rio de Janeiro, RJ: Lamparina, 2008. 245 p.

MUTHER, R. Systematic Layout Planning. 4.ed. Boston: Cahners Books, 2000.

MUTHER, R.; WHEELER, J. D. Planejamento sistemático e simplificado de Layout. São Paulo: IMAM, 2000.

PONZETTO, Gilberto. Mapa de riscos ambientais: NR-5. 2. ed. São Paulo: LTr, 2007. $134 \mathrm{p}$. 
PEREIRA FRANÇA VIEIRA, Natália et al. Aplicação do método SLP para melhoria do arranjo físico: estudo de caso em uma empresa do ramo alimentício. Revista Latino-Americana de Inovação e Engenharia de Produção, v. 2, n. 3, p. 74-85, out. 2014. crossref

PEREIRA, J. Aplicação do método FMEA em Análise de Riscos na Construção. Faculdade de Ciências e Tecnologia da Universidade Nova de Lisboa. (Relatório de Pós-graduação). Portugal, 2012.

ROCHA, F. B. A.; CAMPOS, M. C.; PACHECO, N. O.; SILVEIRA, R. R.; FALANI, S. Y. A. Estudo do layout através do SLP: uma proposta com validação pelo método score para uma fábrica de polpas de frutas. In: ENCONTRO NACIONAL DE ENGENHARIA DE PRODUÇÃO, Belo Horizonte: Abepro, 2011.

SALIBA, T. M. Curso básico de segurança e higiene ocupacional. São Paulo: LTR, 2018.

SALIBA, T. M.; PAGANO, S. C. R. S. Legislação de segurança, acidente do trabalho e saúde do trabalhador. São Paulo: LTR, 2018.

SANTOS, A.; KAWAKAME, M.S; Aplicação do FMEA no gerenciamento de risco de um projeto de cabine de locomotiva em uma metalúrgica. SIMPEP, Bauru: 2014.

SANTOS, Tiago Silva dos et al. Proposta de melhoria de layout para uma oficina de caminhões por meio da aplicação da metodologia PSL. Revista LatinoAmericana de Inovação e Engenharia de Produção, v. 6, n. 9, p. 133 - 147, jun. 2018. crossref

ZORZAN, F.; DORNELES, L.; SERVAT, M.E. FMEA: Orientações conceituais para a aplicação de uma ferramenta de antecipação de falhas. 3a Semana Internacional das Engenharias da FAHOR, Horizontina-RS: 2013.

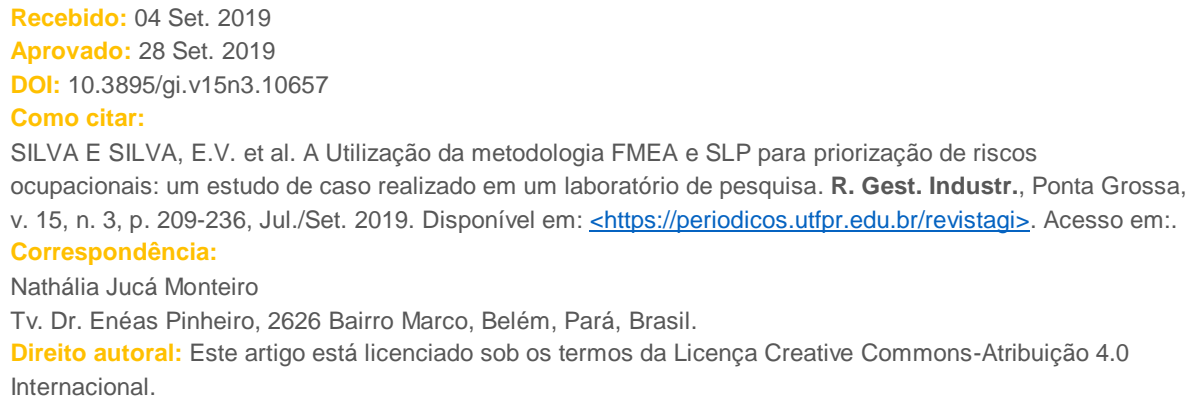

